\title{
BOARD GAME EDUKATIF TENTANG KEPEDULIAN TERHADAP BINATANG PELIHARAAN UNTUK ANAK USIA 6-8 TAHUN
}

\author{
Restu Hendriyani Magh'firoh ${ }^{1}$ \\ Muhammad Nasrulloh ${ }^{2}$ \\ Paulina Sugiarto ${ }^{3}$ \\ Institut Informatika Indonesia,Surabaya ${ }^{l}$ \\ restu@ikado.ac.id
}

\begin{abstract}
Abstrak
Peningkatan kepedulian terhadap binatang peliharaan kepada anak merupakan hal yang penting karena bermanfaat bagi tumbuh kembang anak untuk kedepannya. Sehingga pengenalan mengenai kepedulian terhadap binatang peliharaan sejak kecil perlu dilakukan pada anak. Dalam mengenalkan kepedulian tersebut kepada anak diperlukan cara yang menarik yaitu melalui bermain sambil belajar dengan media board game. Dilakukan pengumpulan data primer melalui wawancara dan penyebaran kuisoner, sedangkan pengumpulan data sekunder melalui pencarian kajian data seperti teori perkembangan anak, psikologi warna, permainan edukatif, teori board game, dan teori ilustrasi. Dari data yang didapat menyatakan bahwa anak-anak suka belajar sambil bermain, oleh karena itu dibuatlah perancangan board game yang bertemakan kepedulian terhadap binatang peliharaan guna mengajarkan cara memperlakukan binatang peliharaan dengan benar. Hasil dari perancangan ini berupa board game Care for Anymal's yang terdiri dari aset seperti papan permainan, kartu, pion, dadu, gacha, token, lembar panduan, dan mini comic. Media pendukung juga dirancang guna membantu penjualan media utama yang berupa merchandise serta media promosi. Perancangan ini dibuat dengan harapan memiliki dampak kepada anak agar dapat memperlakukan binatang peliharaan dengan baik dan menerapkannya ke dalam kehidupannya sehari-hari.
\end{abstract}

Kata kunci: Board Game, Permainan Edukatif, Binatang Peliharaan, Anak-anak.

\begin{abstract}
Increased awareness of pets to children is important because it is beneficial for the child's growth in the future. So that the introduction of caring for pets since childhood needs to be done in children. In
\end{abstract}


introducing such care to children, an interesting way is needed, namely through playing while learning with board game media.Primary data collection was carried out through interviews and questionnaire dissemination, while secondary data was collected through searching data studies such as child development theory, color psychology, educational games, board game theory, and illustration theory. From the data obtained stating that children like to learn while playing, therefore a board game design with the theme of caring for pets is taught to teach animals how to treat pets properly.The results of this design are in the form of Care for Anymal's board game consisting of assets such as board games, cards, pawns, dice, gacha, tokens, guide sheets, and mini comics. Supporting media is also designed to help sales of major media in the form of merchandise and promotional media. This design was made with the hope of having an impact on children to be able to treat pets well and apply them to their daily lives.

Key words: Board Games, Educational Games, Pets, Childrens.

\section{PENDAHULUAN}

Binatang adalah makhluk hidup ciptaan Tuhan yang diperuntukkan untuk melengkapi hidup manusia. Tuhan menciptakan binatang untuk disayangi dan dipelihara oleh manusia seperti pada ayat alkitab Mazmur 8:6-8. Namun masih ada masyarakat yang sering salah mengartikan bahwa binatang yang tidak dilindungi berarti boleh diperlakukan seenaknya saja. Padahal sudah ada hukum yang mengatur itu, seperti pada pasal 302 Kitab Undang-Undang Hukum Pidana. Banyak sekali kasus anak-anak yang menyiksa binatang peliharaan, Menurut Dr. Dono Baswardono, yang merupakan seorang psychoanalyst, graphologist, sexologist, serta marriage $\&$ family therapist mengatakan bahwa sebenarnya bukan hal yang aneh jika anak usia ini sangat senang menjahili binatang peliharaan. Tetapi jika menjahilinya dengan tidak wajar atau yang lebih diartikan sebagai menyiksa binatang peliharaan, orang tua haruslah waspada karena itu bisa jadi sebagai salah satu tanda psikopat.

J.M. Macdonald, seorang psikiater Amerika Serikat dalam artikel (tribunnews.com: 2014) meneliti perilaku dari sekitar 100 orang penjahat. Ciri-ciri pertama adalah suka menyiksa binatang peliharaan seperti kasus Jeffrey Dahmer yang fotonya tersebar saat kecil ia memegang kucing dengan posisi mencekik 
kucing yang ia pegang. Ciri-ciri yang kedua adalah piromania yaitu penyakit gangguan mental yang ditandai dengan penderita akan merasa lega atau senang ketika membakar sesuatu. Ciri yang ketiga ialah enuresis atau ketidakmampuan seseorang dalam menahan urin, seperti kasus Andrei Chikatilo sang pembunuh berantai yang waktu kecil dipukuli ibunya setiap mengompol hingga akhirnya dia merasa senang melihat anak lain yang dipukul karena kesalahan mereka. Dan ciri lainnya adalah suka melanggar peraturan, berbohong tanpa menyesal, mem-bully, dan tidak peka.

Dari kasus-kasus tersebut sebaiknya anak sudah mulai diajarkan menyayangi binatang peliharaan sejak usia 6-8 tahun. Usia 6-8 tahun adalah masa yang paling baik untuk mengajarkan segala sesuatu yang baik kepada anak. Karena pada masa ini anak senang mencontoh kebiasaan orang tua ataupun orang terdekatnya dan melakukannya di kehidupan sehari-hari mereka. Sehingga menanamkan rasa kepedulian terhadap binatang peliharaan kepada anak-anak usia 6-8 tahun yang masih dalam tahap pertumbuhan dan perkembangan, memungkinkan anak lebih cepat menerima informasi dan mempraktekkannya terhadap lingkungan di sekitarnya. Menurut Hibana (2002:5), usia dini merupakan periode masa emas bagi perkembangan anak dimana tahap perkembangan otak pada anak usia dini menempati posisi yang paling vital yakni meliputi $80 \%$ perkembangan otak anak. Makna pendidikan anak usia dini adalah upaya yang terencana dan sistematis yang dilakukan oleh pendidik atau pengasuh anak usia 0-8 tahun dengan tujuan agar anak mampu mengembangkan potensi yang dimiliki secara optimal.

Dunia anak adalah dunia bermain dan gaya belajar anak yang paling ampuh adalah melalui permainan. Menurut Piaget dalam (Sumarno: 2000), karakteristik anak sekolah dasar dapat berkembang lebih cepat ketika mereka berinteraksi satu sama lain. Dengan perkembangan anak yang seperti itu, board game dirasa cocok untuk membuat anak memahami kepedulian terhadap binatang peliharaan. Bahkan anak dapat berkembang lebih cepat karena dengan board game anak dapat berinteraksi satu sama lain. Board game adalah permainan papan yang dapat dimainkan oleh dua orang atau lebih. Dengan menggunakan media ini anak SD 
akan lebih menyukainya karena mereka lebih cenderung senang bermain game daripada hanya membaca atau mendengarkan sesuatu.

Dari permasalahan-permasalahan tersebut, maka pentinglah dibuatnya board game edukatif tentang kepedulian terhadap binatang peliharaan. Ilustrasi yang ada pada board game akan membantu anak lebih memahami permainan. Melalui board game ini diharapkan anak-anak dapat memperlakukan binatang peliharaan dengan baik dan tidak melukai atau menyakiti binatang peliharaan yang ingin ia ajak bermain.

\section{KAJIAN TEORI}

\section{Teori Perkembangan Anak Usia 6-8}

Pada usia 6-8 tahun, kemampuan kognitif anak mengalami perkembangan yang sangat pesat. Hal ini dikarenakan dunia dan minat anak semakin luas sehingga pengertian tentang manusia dan objek-objek semakin bertambah. Pada usia ini pula daya pikir anak berkembang ke arah berpikir konkrit, rasional, dan objektif. Dalam teori kognitif Piaget, pemikiran anak usia ini disebut pemikiran operasional konkrit di mana aktivitas mental difokuskan pada objek dan peristiwa yang dapat diukur atau nyata. Pada usia ini pula, anak mulai mengembangkan pemikiran kritis.

Sedangkan perkembangan sosial pada anak usia 8 tahun ditandai dengan adanya perluasan hubungan dengan orang dewasa dan teman lain di sekitarnya. Selain dari itu, pada usia ini anak mulai membentuk ikatan baru dengan teman sebaya (peer group) atau dengan teman sekelas, sehingga ruang gerak hubungan sosialnya menjadi lebih luas. Pada usia ini pula, anak mulai memiliki kesanggupan untuk menyesuaikan diri dari sifat egosentris (berfokus pada diri sendiri) kepada sikap yang kooperatif (bekerjasama) atau sosiosentris (memperhatikan kepentingan orang lain).

\section{Perilaku Terhadap Binatang Peliharaan}

Usia 6-8 tahun adalah masa ketika anak senang untuk meniru lalu merealisasikannya ke dalam kehidupannya. Tindakan yang dilakukannya pada usia 
tersebut sangatlah penting untuk membentuk masa depannya. Sifat-sifat yang baik akan berdampak baik juga untuk masa depannya, begitu pula dengan caranya memperlakukan binatang peliharaannya. Sifat anak dapat dilihat dari cara-cara menyayangi binatang peliharaannya. Menurut Syaikh Abu Bakar Jabir Al-Jaza'iri dalam (Sasongko: 2019), menyayangi binatang adalah bagian dari ajaran agama islam, muslim beranggapan bahwa kebanyakan hewan adalah makhluk mulia, maka dari itu ia menyayanginya karena Allah sayang kepada mereka dan ia selalu berpegang teguh kepada etika dan adab. Berikut bentuk dari menyayangi binatang peliharaan, (1) Memperhatikan pemberian makanan (2) Tidak memeras tenaga binatang secara berlebihan (3) Tidak menyiksa.

\section{Permainan Edukatif}

Permainan adalah sesuatu yang digunakan untuk bermain dengan aturanaturan tertentu. Menurut kamus besar bahasa Indonesia online permainan adalah sesuatu yang digunakan untuk bermain atau dipermainkan. Dapat disimpulkan bahwa permainan adalah sesuatu yang digunakan untuk bersenang-senang dengan teknik atau aturan tertentu.

Menurut kamus besar bahasa Indonesia online edukasi adalah bersifat mendidik atau berkenaan dengan pendidikan. Dapat disimpulkan bahwa permainan edukatif adalah sesuatu yang digunakan untuk bermain dengan sifat mendidik. Bermain dapat meningkatkan motivasi anak untuk belajar, dengan adanya interaksi dengan permainan maka ingatan pada anak akan terus melekat. Menurut (Clark, 2006 dalam Wulandari, 2012) untuk menciptakan motivasi belajar sebesar motivasi dalam permainan, dibutuhkan guru yang sangat berkompeten di bidangya. Dengan adanya permainan edukatif potensi belajar seorang anak akan sangat meningkat.

\section{Board Game}

Board game adalah permainan yang dilakukan di atas papan dan dimainkan lebih dari satu orang dalam satu tempat dan papan yang sama (Limantara, Waluyanto, Zacky, 2015). Para pemain dapat berinteraksi secara langsung dengan pemain lain sehingga dapat membangun interaksi antar sesama. Board game adalah media permainan yang mendidik dan mendekatkan keluarga. 
Pada masa kini ketika berkumpul dengan keluarga kebanyakan anggota keluarga bermain gadget sendiri-sendiri daripada menikmati waktu berkumpul, dengan adanya board game dapat membuat acara berkumpul keluarga terasa lebih hangat dan medekatkan keluarga kembali.

\section{Teori Ilustrasi}

Dalam board game terdapat ilustrasi yang dipakai sebagai penjelas dari suatu komponen yang ada di dalamnya. Ilustrasi berasal dari bahasa latin illustrate, yang memiliki arti menjelaskan atau menerangkan, dalam arti luas karya seni rupa yang bertujuan untuk memperjelas sesuatu atau menerangkan sesuatu yang dapat berupa cerita atau naskah, musik atau gambar (Rasjoyo dalam Kristanto, 1994). Dengan adanya ilustrasi, anak akan merasa lebih terbantu untuk memperjelas maksud yang ada pada suatu gambar gambar atau tulisan tersebut.

\section{METODE PENELITIAN}

Dalam pengumpulan data, penulis menggunakan teknik kualitatif dan kuantitatif. Teknik pengumpulan data secara kualitatif yang dilakukan oleh penulis adalah wawancara dengan guru sekolah dasar dan komunitas pecinta binatang peliharaan di Surabaya. Teknik pengumpulan data secara kuantitatif didapatkan melalui kuesioner yang dibagikan kepada anak-anak usia 6-8 tahun sesuai dengan target audiens dari perancangan ini. Metode perancangan dimulai dari pembuatan konsep dasar permainan mulai dari nama permainan, aturan permainan (komponen, persiapan, dan cara bermain). Selanjutnya melakukan proses desain karakter dan desain komponen dalam board game mulai dari sketsa hingga digital dan percetakan.

\section{HASIL DAN PEMBAHASAN}

Board game ini dirancang sebagai media untuk mengajarkan anak supaya lebih peduli terhadap binatang peliharaan dan mengingatkan orang tua agar mendidik anaknya untuk peduli terhadap binatang peliharaan. Board game adalah media yang digunakan. Board game memiliki pion berupa clay yang menarik untuk 
dimainkan oleh anak usia 6-8 tahun. Board game berukuran 41 x $41 \mathrm{~cm}$ dan menggunakan mdf dengan dilapisi stiker sebagai bahannya.

\section{Tahap Perancangan (Design)}

Pada perancangan board game binatang peliharaan ini dijelaskan semua proses dari awal hingga siap dimainkan oleh anak.

Tabel 1. Spesifikasi Media

\begin{tabular}{|l|l|l|l|}
\hline \multicolumn{2}{|l|}{ Media Utama } \\
\hline No. & Jenis & Ukuran & Bahan \\
\hline 1. & Papan Permainan & $41 \mathrm{~cm} \mathrm{x} 41 \mathrm{~cm}$ & MDF \\
2. & Kartu & $6,3 \times 8,8 \mathrm{~cm}$ & ArtPaper 260gr \\
3. & Pion & D: $3 \mathrm{~cm}$ & Clay \\
4. & Token & D: $4 \mathrm{~cm}$ & Akrilik \\
5. & Gacha & D: $7,5 \mathrm{~cm}$ & Plastik \\
6. & Panduan Bermain & $38,3 \times 22,9 \mathrm{~cm}$ & ArtPaper 210gr \\
7. & Dadu & $1,4 \mathrm{~cm}$ & Plastik \\
\hline
\end{tabular}

Sumber Tabel: Dokumentasi Penulis

a. Konsep Dasar

Permainan ini terfokus pada pengenalan kepada anak mengenai kepedulian terhadap binatang peliharaan. Dalam perjalanan pemain akan mendapatkan kartu binatang, kartu makanan binatang, dan kartu tempat tinggal binatang. Dari kartu tersebut, pemain dapat belajar mengenal binatang peliharaan beserta jenis makanan dan tempat tinggalnya. Untuk mendapatkan pion binatang, pemain harus mengumpulkan 3 pasang kartu yang sesuai.

b. Nama Permainan

Judul pada board game ini adalah "Care For Anymals". "Anymals" diambil dari kata any dan animals. Judul tersebut memiliki arti kepedulian kepada banyak binatang peliharaan.

c. Cara Permainan

Komponen:

1. 16 Kartu Binatang

2. 16 Kartu Makanan Binatang 
3. 16 Kartu Tempat Tinggal Binatang

4. 4 Pion Karakter Manusia8 Token Karakter Binatang

5. 1 Gacha

6. 1 Dadu

Persiapan:

1. Letakkan token binatang pada lingkar ungu.

2. Letakkan gacha pada lingkar pink.

3. Alur permainan dimulai dari sisi start, terus maju sesuai dengan arah jarum jam untuk berpindah ke sisi lain.

4. Semua pemain memilih karakter sesukanya, lalu letakkan pion karakter manusia pada garis start.

5. Tentukan siapa yang mendapatkan giliran pertama memulai permainan dengan cara mendapatkan angka dadu terbesar.

Cara Bermain:

1. Setiap ronde, pemain akan melempar dadu dan maju sesuai angka dadu yang keluar.

2. Jika berhenti di papan berwarna pink maka pemain berhak mendapatkan kartu berwarna pink yaitu kartu binatang.

3. Jika berhenti di papan berwarna ungu maka pemain berhak mendapatkan kartu berwarna ungu yaitu kartu makanan.

4. Jika berhenti di papan berwarna biru maka pemain berhak mendapatkan kartu berwarna biru yaitu kartu tempat tinggal.

5. Jika berhenti di pojok papan berwarna oranye maka pemain berhak mengambil 1 kartu dari temannya sesuai keinginannya.

6. Jika berhenti di sisi papan sebelah garis start yang bergambarkan 3 kartu, pemain berhak memilih salah satu kartu dari dek.

7. Pemain haruslah mengumpulkan 3 pasang kartu yang sesuai. (contoh: anjing - makanan anjing - rumah anjing)

8. Pemain yang sudah mengumpulkan 3 pasang kartu tersebut, harus memutar gacha untuk mendapatkan binatang peliharaan yang sesuai dengan kartu yang didapat. 
9. Jika mendapatkan manik berwarna pink : boleh mengambil token. Sedangkan, jika mendapat manik berwarna biru : tidak mendapatkan token.

10. Jika mendapat manik lebih dari satu maka manik dengan warna terbanyak yang dihitung. Contoh: 2 manik (pink biru) maka boleh memilih salah satu, 3 manik (pink pink biru) maka yang dihitung adalah manik berwarna pink.

11. Jika mendapatkan manik berwarna biru, haruslah menunggu 1 putaran barulah boleh memutar gacha lagi.

12. Pemain dengan 2 token binatang atau 1 token binatang dengan 3 pasang kartu akan langsung memenangkan permainan.

13. Jika token binatang peliharaan pada papan sudah habis, maka jika pemain berhasil mengumpulkan pasangan kartu tetap tidak memperoleh token binatang peliharaan.

14. Kartu yang sudah terpakai (berhasil mendapatkan pion binatang peliharaan) tidak dikembalikan ke dalam dek lagi.

d. Desain Media

1. Logo

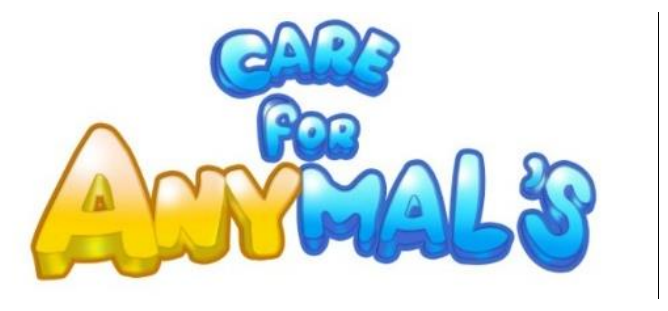

Gambar 1. Logo Care for Anymal's

Sumber: Dokumentasi Penulis 
2. Board Game

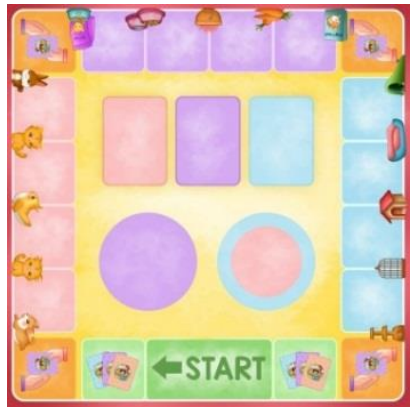

Gambar 2. Board Game

Sumber: Dokumentasi Penulis

3. Packaging

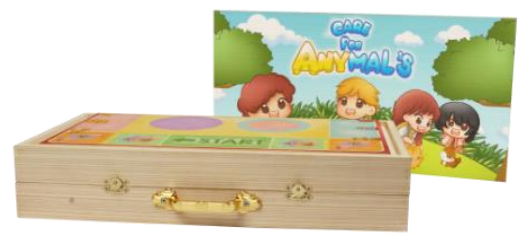

Gambar 3. Packaging

Sumber: Dokumentasi Penulis

4. Kartu

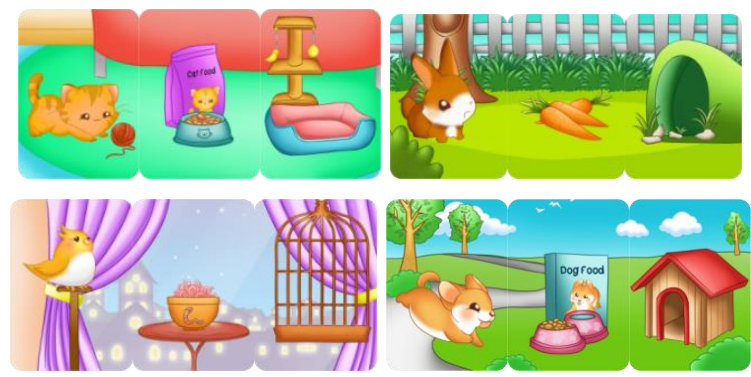

Gambar 4. Kartu

Sumber: Dokumentasi Penulis 


\section{Pion}

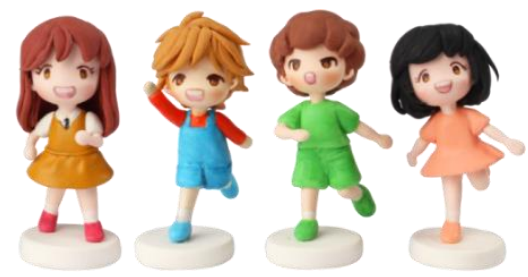

Gambar 5. Pion

Sumber: Dokumentasi Penulis

6. Token

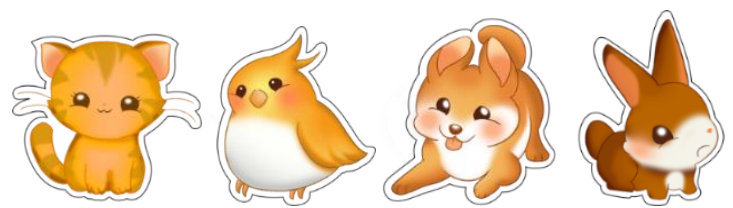

Gambar 6. Token

Sumber: Dokumentasi Penulis

7. Lembar Panduan Bermain

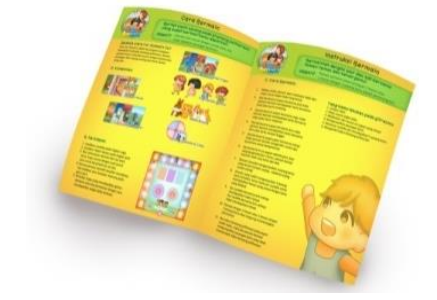

Gambar 7. Lembar Panduan

Sumber: Dokumentasi Penulis

8. Mini Comic

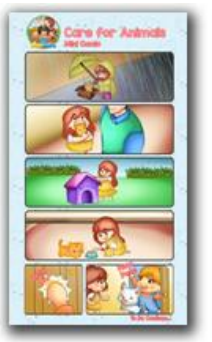

Gambar 8. Mini Comic

Sumber: Dokumentasi Penulis 


\section{SIMPULAN DAN SARAN}

\section{Simpulan}

Fenomena yang sering terjadi pada saat ini adalah kekerasan terhadap binatang peliharaan, maka haruslah diajarkan mengenai kepedulian terhadap binatang peliharaan dimulai dari usia dini. Berdasarkan hasil pencarian data yang didapat melalui wawancara dan kuisoner, maka perlu dilakukan perancangan board game untuk mengenalkan kepedulian terhadap binatang peliharaan kepada anak usia 6-8 tahun. Hal ini bertujuan untuk meningkatkan kepedulian anak terhadap binatang peliharaan, serta memberi pengetahuan mengenai memelihara binatang peliharaan. Merancang board game yang menarik bagi anak usia 6-8 tahun dengan membuat tema binatang peliharaan akan meningkatkan kepedulian anak terhadap binatang peliharaan. Dengan cara bermain menyocokkan kartu dengan gambar binatang peliharaan, tempat tinggal, dan makanannya akan membuat anak lebih mengerti mengenai cara memelihara binatang peliharaan dengan benar. Ilustrasi yang dibuat menarik dengan menghadirkan suasana ceria dan binatang peliharaan yang lucu akan membuat anak semakin tertarik untuk memainkan board game Care for Anymal's.

Hasil dari perancangan ini adalah 1 board game yang berjudul "Care for Anymal's". Media pendukung berupa beberapa merchandise seperti: kaos, kipas, bantal, botol minum, gantungan kunci, kotak makan, bubble, penggaris, pensil, penghapus, rautan, dan notebook kecil. Media promosi berupa poster, x-banner, brosur, dan instagram. Media pendukung tersebut menggunakan karakter binatang peliharaan yang terdapat dalam board game, hal tersebut akan meningkatkan kesukaan anak terhadap binatang peliharaan.

\section{Saran}

Mengenalkan kepedulian terhadap binatang peliharaan pada anak sangatlah penting, oleh sebab itu penulis menyarankan kepada orang tua untuk mengajarkannya kepada anak sejak dini. Manfaat dari mengenalkan kepedulian terhadap binatang peliharaan itu sendiri adalah supaya anak mengerti tentang perbuatan baik dan buruk yang dilakukannya kepada binatang peliharaan serta cara memelihara binatang peliharaan dengan benar dan meningkatkan sosialisasi 
terhadap sesama melalui bermain board game. Setelah melewati proses perancangan board game "Care for Anymal's", penulis dapat memberikan saran bagi pembaca yang akan melakukan perancangan dengan topik serupa agar dapat merancang segala sesuatunya dengan matang. Mulai dari proses sketsa diperlukannya rule yang matang agar permainan dapat berjalan dengan adil. Dibutuhkannya percobaan terlebih dahulu, kemudian ketika mencetak cobalah terlebih dahulu agar warna yang diinginkan dapat sesuai. Cobalah board game sebanyak mungkin agar dapat mengerti konsep dari bermain board game.

\section{DAFTAR PUSTAKA}

Hibana. 2002. Konsep Dasar Pendidikan Anak Usia Dini. Yogyakarta: PGTKI Press

Kamus Besar Bahasa Indonesia (KBBI). Diakses pada tanggal 5 Juni 2018 (https://kbbi.web.id/)

Limantara, Daniel, Heru Dwi Waluyanto, Aznar Zacky. (2015). Perancangan Board Game Untuk Menumbuhkan Nilai-Nilai Moral Pada Remaja. Diakses pada Tanggal 25 Oktober 2018

(http://publication.petra.ac.id/index.php/dkv/article/download/3219/2909)

Sumarno, Paul. 2000. Teori Perkembangan Kognitif Jean Piaget. Kanisius

Tribunjogja. (2014). Pembantaian Kucing. Diakses pada Tanggal 15 Mei 2019 Pukul 13.42 WIB (http://jogja.tribunnews.com/topic/pembantaian-kucing)

Wulandari, Suci Ningsih. (2015). Penggunaan Permainan Tradisional pada Kemampuan Berhitung Permulaan pada Anak Usia 4-5 Tahun di TK. Beringin Raya Bandar Lampung. Diakses Pada tanggal 27 Oktober 2018 (http://jurnal.fkip.unila.ac.id/index.php/PAUD/article/view/10024)

Sasongko, Agung. 2019. Sayangi Binatang. Diakses pada tanggal 27 Oktober 2018 (https://republika.co.id/berita/dunia-islam/islamnusantara/19/03/03/pns2ch313-sayangi-binatang) 